\title{
Circadian rhythm sleep disorders
}

\author{
This article was published in the following Dove Press journal: \\ ChronoPhysiology and Therapy \\ 24 May 2012 \\ Number of times this article has been viewed
}

\author{
Bhanu P Kolla ${ }^{1,2}$ \\ R Robert Auger ${ }^{1,2}$ \\ Timothy I Morgenthaler' \\ 'Mayo Center for Sleep Medicine, \\ ${ }^{2}$ Department of Psychiatry and \\ Psychology, Mayo Clinic College of \\ Medicine, Rochester, MN, USA
}

\begin{abstract}
Misalignment between endogenous circadian rhythms and the light/dark cycle can result in pathological disturbances in the form of erratic sleep timing (irregular sleep-wake rhythm), complete dissociation from the light/dark cycle (circadian rhythm sleep disorder, free-running type), delayed sleep timing (delayed sleep phase disorder), or advanced sleep timing (advanced sleep phase disorder). Whereas these four conditions are thought to involve predominantly intrinsic mechanisms, circadian dysrhythmias can also be induced by exogenous challenges, such as those imposed by extreme work schedules or rapid transmeridian travel, which overwhelm the ability of the master clock to entrain with commensurate rapidity, and in turn impair approximation to a desired sleep schedule, as evidenced by the shift work and jet lag sleep disorders. This review will focus on etiological underpinnings, clinical assessments, and evidence-based treatment options for circadian rhythm sleep disorders. Topics are subcategorized when applicable, and if sufficient data exist. The length of text associated with each disorder reflects the abundance of associated literature, complexity of management, overlap of methods for assessment and treatment, and the expected prevalence of each condition within general medical practice.
\end{abstract}

Keywords: circadian rhythm sleep disorders, assessment, treatment

\section{Introduction}

Sleep and wakefulness are driven by two interrelated processes termed process $\mathrm{C}$ and process S. ${ }^{1}$ Process $\mathrm{C}$ drives wakefulness, and is dependent upon an intrinsic circadian rhythm. It variably opposes process $\mathrm{S}$, a homeostatic drive to sleep that is proportional to the amount of preceding wakefulness in humans. Process $\mathrm{C}$ exhibits a dimunition in strength during both early morning and early afternoon hours, and Process S exhibits its peak strength subsequent to approximately 40 hours of sleep deprivation (Figure 1). ${ }^{2}$

The suprachiasmatic nucleus, located within the hypothalamus, houses the master

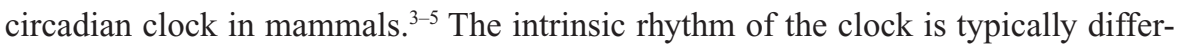
ent from 24 hours, and extrinsic stimuli, known as zeitgebers (German neologism meaning "time givers"), synchronize it to a 24-hour cycle. ${ }^{6,7}$ This process of aligning the biological clock and environmental cycles is known as entrainment. Photic stimulation is the most important zeitgeber for most species. ${ }^{8}$ Scheduled sleep, social activities, and timing of meals are other important factors that influence the circadian clock. ${ }^{9}$ Intrinsically photosensitive retinal ganglion cells, which are most sensitive to blue light, appear to be particularly integral with respect to the photic entrainment of circadian rhythms. These cells contain the pigment melanopsin, and are not involved in vision. ${ }^{10}$
Correspondence: Timothy I Morgenthaler Mayo Center for Sleep Medicine, Mayo Clinic College of Medicine, Rochester, MN, USA

Email morgenthaler.timothy@mayo.edu 


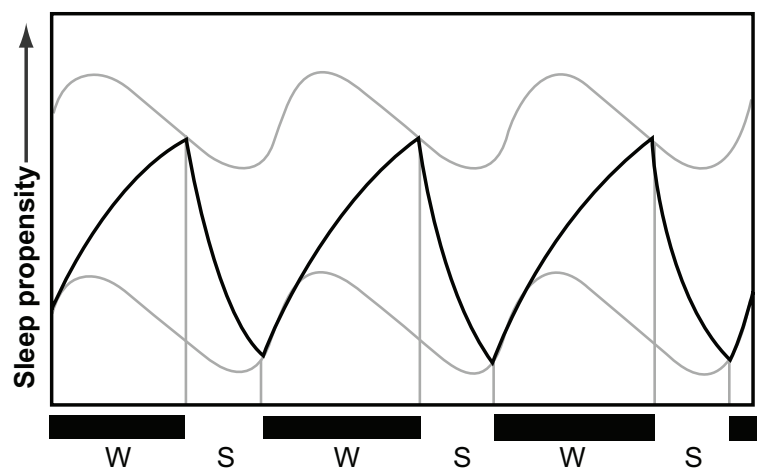

Figure I Two-process model of sleep regulation.

Notes: The solid line represents Process $S$ which accrues with wakefulness (W) and subsides with sleep (S). The dotted line represents Process $C$ and reflects the circadian drive for wakefulness.

Copyright (C) 2007, Elsevier. Modified with permission from Beersma DG, Gordijn MC. Circadian control of the sleep-wake cycle. Physiol Behav. 2007;90(2-3):190-195. ${ }^{161}$

Recent studies have shown that rod cells in the retina can also drive circadian photoentrainment at light intensities which are below the threshold for photopic vision. ${ }^{11}$

The timing of melatonin secretion and the core body temperature minimum serve as useful proxy measures of the intrinsic circadian system. ${ }^{12}$ While absent or minimal during the biological day, robust melatonin secretion commences around 14 hours following the natural time of awakening. The timing of this event within controlled dim lighting conditions is referred to as the dim light melatonin onset. ${ }^{13}$ The core body temperature minimum typically occurs several hours prior to the time of natural awakening. The light and melatonin phase response curves are pictorial representations of the effects of these respective stimuli on intrinsic circadian rhythms when administered at various times during the biological day (Figure 2). ${ }^{14}$

\section{Jet lag sleep disorder Description and predisposing factors}

Jet lag presents with both nocturnal sleep disturbances and impaired daytime alertness, in addition to other symptoms such as general malaise and gastrointestinal distress. ${ }^{15}$ Although of minor consequence to some, debilitation can occur to a degree that engagement in business or other productive activities is compromised. The severity of impairment is dependent upon numerous variables. As would be predicted based upon the typical greater than 24-hour length of the human circadian period, westward travel is generally less taxing than eastward travel (as it requires a phase delay, rather than a phase advance). ${ }^{16}$ Because maximal daily delays and advances can occur in the order of 2 and 1.5 hours, respectively, ${ }^{16,17}$ traversal of up to two time zones is only transiently problematic for most individuals (if at all). The degree to which travel occurs in excess of this "window" correlates with the rapidity at which the circadian pacemaker can re-entrain, which in turn contributes to the duration and magnitude of associated symptoms (Table 1). An individual's innate circadian preference (ie, their relative "morningness" or "eveningness") may also confer a greater

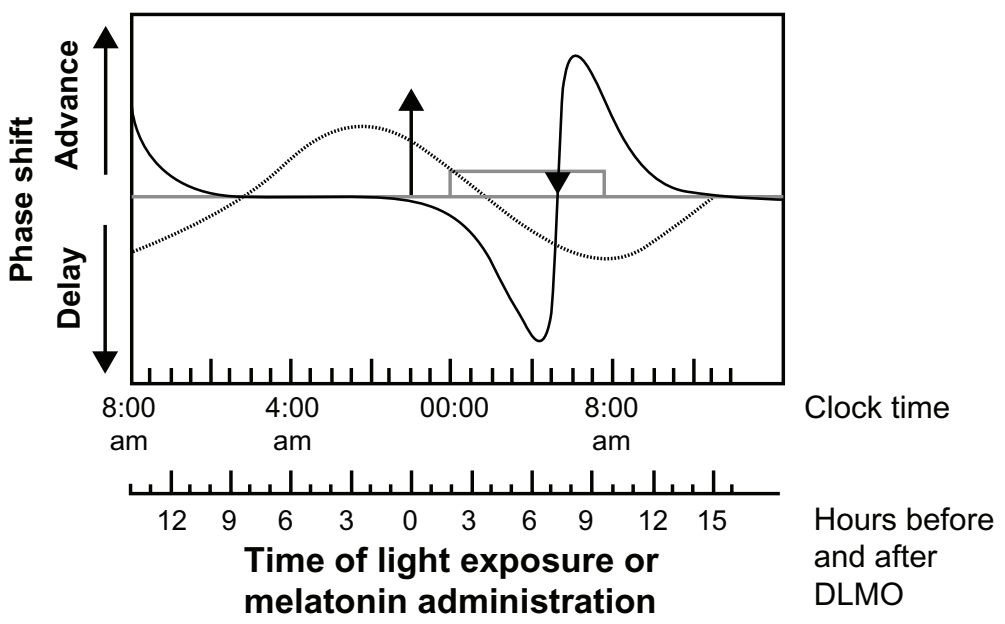

Figure 2 A schematic human phase response curve to light (dark line) and a phase response curve to exogenous melatonin (dashed line). The y-axis shows the direction and relative magnitude of the phase shift produced by the administration of light or melatonin at various times, which are shown on the x-axis. The $\mathrm{x}$-axis covers more than 24 hours in order to illustrate the phase response curves better. The rectangle represents the sleep episode, the triangle represents the core body temperature minimum, and the arrow represents the DLMO. The clock time axis shows the DLMO at about 22:00 hours, the sleep interval from 00:00-08:00 hours, and the core body temperature minimum at about 05:00 hours. These represent typical times and phase relationships among these rhythms when the circadian clock is entrained to a 24 -hour day. The light phase response curve is a schematic based upon the results of numerous studies. The melatonin phase response curve is based upon a single study using $0.5 \mathrm{mg}$ doses of melatonin, as already reviewed by Lewy. ${ }^{126}$ Copyright (c) 2010, American College of Physicians. Reprinted with permission from Burgess HJ, Eastman CT. Prevention of Jet Lag. 20I0. Available from http://pier.acponline. org/physicians/screening/prev I0I5/prev1015.html. Accessed January I2, 2012.

Abbreviation: DLMO, dim light melatonin onset. 
Table I Factors related to development of jet lag sleep disorder

\begin{tabular}{ll}
\hline Factor & Impact \\
\hline Direction of travel & $\begin{array}{l}\text { Westward travel generally of less impact } \\
\text { than eastward travel }\end{array}$ \\
Distance of travel & $\begin{array}{l}\text { Traversing } \leq 2 \text { time zones of less impact } \\
\text { than }>2 \text { time zones }\end{array}$ \\
Individual innate & $\begin{array}{l}\text { Morning preference: travel east may } \\
\text { be easier than for those with evening }\end{array}$ \\
circadian preference & $\begin{array}{l}\text { preference. Vice versa for westward travel } \\
\text { The adjustments are neither faster nor } \\
\text { Phase tolerance }\end{array}$ \\
slower for those with greater or lesser \\
phase tolerance, but symptoms may be less \\
in the more tolerant \\
Sleep deprivation before and during travel, \\
travel discomfort, alcohol, and/or caffeine \\
intake, dehydration
\end{tabular}

or lesser ability to adjust to a particular time shift, but this has not been systematically assessed. One's ability to sleep at an abnormal circadian phase ("phase tolerance") also affects the degree to which adverse symptoms are experienced, and this adaptability varies among individuals. ${ }^{18,19}$

Proper exposure and avoidance of light upon arrival at the travel destination can facilitate adaptation to the local time zone, while improper practices can impede this adaptation. In a common process known as antidromic re-entrainment, phase shifts occur in a direction opposite to the shift in external time (eg, a phase delay instead of a phase advance occurs subsequent to eastward travel), the occurrence of which is dependent upon the number of time zones crossed and ambient light exposure in the local area, as reviewed elsewhere. ${ }^{17,20}$ Preventative strategies to reduce the occurrence of this phenomenon will be discussed in more detail below.

Clearly, numerous other variables related to extensive travel contribute to the overall symptoms of travel fatigue, in the absence of a direct circadian correlate. These include sleep deprivation preceding or on the flight, travel-related discomfort, ${ }^{21,22}$ and excessive alcohol and/or caffeine intake en route. ${ }^{16}$ All of these factors need to be considered in evaluating patients with jet lag syndrome and in planning treatment options.

\section{Assessment}

Clinical history is sufficient to diagnose impairments related to jet lag.

\section{Treatment}

The goal of treatment is to achieve circadian realignment in the most rapid and efficient way possible and to minimize associated symptoms during the interim period. Prior to proceeding with a treatment plan, however, it is important to determine the length of stay in the new time zone. Frequent shifts to differing time zones (such as those required by business travelers) are impossible to accommodate, and the individual may actually do better remaining on the homebased schedule, insofar as this is practical. In a balanced crossover field study, comparisons were made between subjects who kept home-based sleep hours versus those that adopted destination hours, during a 2-day stay after a 9-hour westward flight. ${ }^{22}$ The group that remained on home-based hours exhibited reduced sleepiness and fewer symptoms of jet lag than the group that adopted the destination time. Though this could be recommended as a treatment strategy, most travelers would find that it would curtail social activities, and adherence is likely to be poor.

\section{Timed light exposure}

To counteract the antidromic effect described above and to hasten phase shifts, Smith and Eastman have devised strategic plans of exposure to or avoidance of light, depending upon whether phase delays or advances are desired..$^{23}$

Travel to the east spanning less than eight time zones favors an advance of the circadian phase, which is facilitated by avoiding light approximately 3 hours prior to the estimated core body temperature minimum, and exposing oneself to bright light for approximately 3 hours thereafter. This is performed after allowing for a daily advance of about 1 hour in the core body temperature minimum until desired sleep time is achieved. Estimations of core body temperature minimum are based upon known relationships with respect to habitual wake time, prompting one to estimate core body temperature minimum timing either 2 or 3 hours prior to sleep offset, depending upon whether one typically sleeps up to 7 hours or more than 7 hours, respectively. ${ }^{24-26}$

Travel to the west generally favors phase delays, which can be achieved in approximately 2-hour increments (reflecting the greater ease of delaying the clock), by following similar principles. In the opposite pattern, subjects expose themselves to light for approximately 3 hours prior to the core body temperature minimum and avoid light for approximately three hours thereafter (see Figure 3 as an example). Light exposure can be achieved by natural means or using portable artificial sources; avoidance can be accomplished by using dark glasses or remaining in a dark room.

\section{Nocturnal medication administration for jet lag}

Melatonin at doses of $2-8 \mathrm{mg}$ has been found to improve night time sleep as well as improve daytime symptoms of 


\section{Jet lag plan for 9 time zones east}

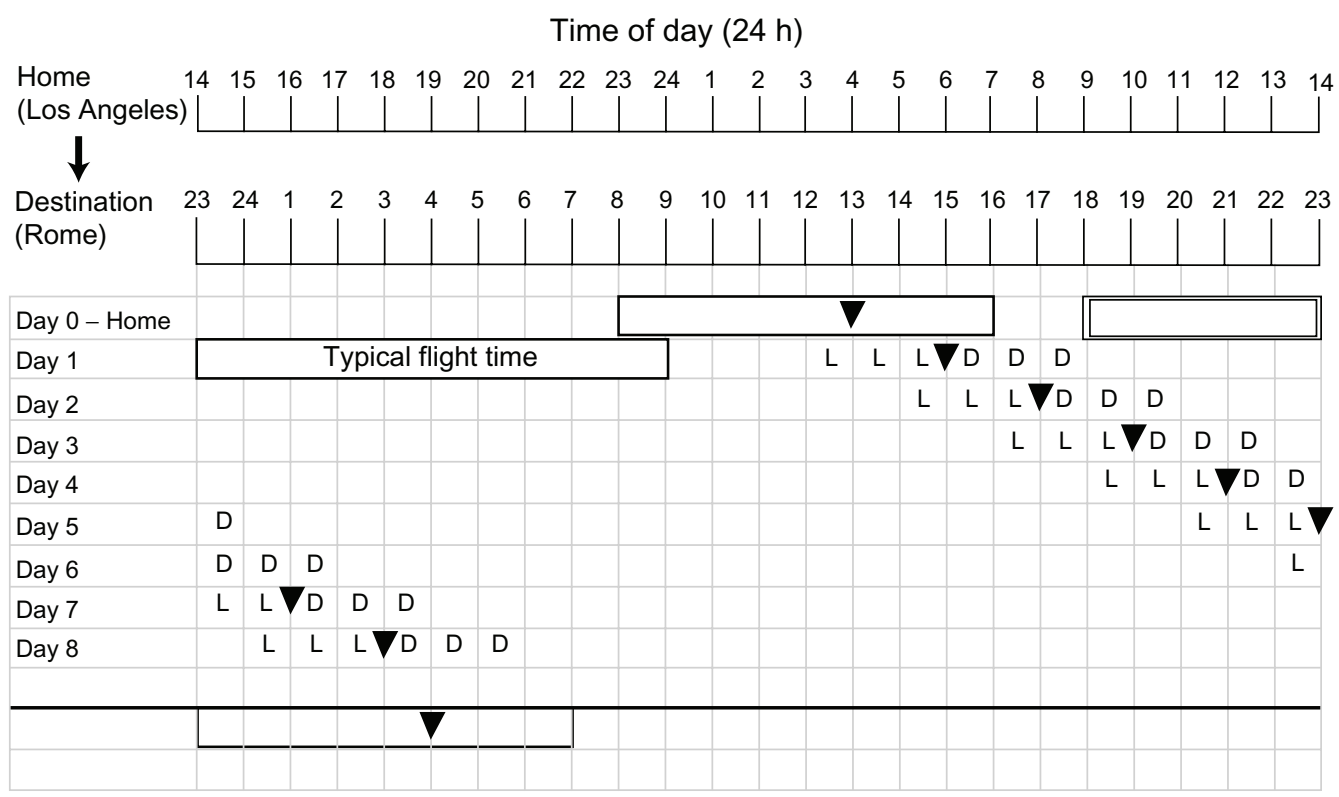

Figure 3 Diagram demonstrating a flight from Los Angeles to Rome, nine time zones east. The rectangle on day 0 shows the habitual sleep period, with the inverted triangle representing the core body temperature minimum at home time zone. The rectangle on day I shows the time of the flight from Los Angeles to Rome. The rectangle at the bottom of the figure represents the desired sleep schedule, with the inverted triangle representing the core body temperature minimum at the travel destination (Rome). The areas denoted by the letters " $D$ " and " $L$ " represent times when darkness and light should be sought, respectively. The depicted light/dark pattern should result in average daily phase shifts of 2 hours.

Copyright $@ 2010$, American College of Physicians. Reprinted with permission from Burgess HJ, Eastman CT. Prevention of Jet Lag. 20I0. Available from http://pier.acponline. org/physicians/screening/prev1015/prev1015.html. Accessed January 12, 2012. ${ }^{162}$

jet lag. ${ }^{24,25}$ Immediate-release preparations appear to perform better than controlled-release formulations. ${ }^{26}$ Although most studies have examined the efficacy of melatonin for jet lag occurring subsequent to eastward travel, ${ }^{26-29}$ a single study examined its use in travel to the west and found it to be efficacious. ${ }^{25}$ Melatonin use has been studied using a variety of different dosing schedules. One regimen stipulates that subjects begin to use the supplement at the anticipated destination bed time 3 days prior to departure, en-route, and upon arrival. ${ }^{30}$ Another dosing regimen commences treatment prior to bedtime solely upon arrival at the travel destination. While there is evidence to support both schedules, a comparison study (involving westward travel) demonstrated superior outcomes with the simpler regimen. ${ }^{25}$ The simpler regimen also has the advantage that it is more likely to be followed.

\section{Benzodiazepine receptor agonists}

Prescription and over-the-counter hypnotic agents are commonly used to counteract insomnia associated with jet lag. While benzodiazepine receptor agonists significantly improve subjective and objective night-time sleep parameters, their impact on daytime symptoms of jet lag is unclear. ${ }^{26,27,31-33}$ In one head-to-head comparison, the benzodiazepine receptor agonist, zopiclone (5 mg), and melatonin (2 mg) were equipotent. ${ }^{27}$ In another study that compared melatonin ( $5 \mathrm{mg}$ ) with a similar medication (zolpidem, $10 \mathrm{mg}$ ) and a combination group (zolpidem + melatonin), zolpidem exhibited superior outcomes, and no benefit was conferred by use of these substances in combination. Adverse events were nevertheless recorded more frequently in the zolpidem group. ${ }^{26}$ Clinicians will need to balance the risk of adverse events with the degree of impairment perceived by the patient in order to help them choose an appropriate agent.

\section{Stimulants}

Armodafinil at doses of $50 \mathrm{mg}$ and $150 \mathrm{mg}$ was compared with placebo in a simulation study. Armodafinil reduced objective sleepiness as measured by a multiple sleep latency test and also resulted in subjective improvements in jet lag symptoms. ${ }^{34}$ Caffeine (in the form of caffeinated beverages) is ostensibly the first-line "medication" utilized to combat jet lag. At a dose of $300 \mathrm{mg}$ each morning, it was found to result in quicker realignment of circadian rhythms as compared with melatonin. ${ }^{35}$ However, caffeine also resulted in more disrupted night-time sleep. ${ }^{36}$ 


\section{Shift work sleep disorder Description and predisposing factors}

Shift work is a broad term that typically includes rotating and permanent night work. Although difficult to extricate from the normal demands such work imposes, shift work sleep disorder applies to patients who complain chronically of insomnia or sleepiness at times that are not conducive to the externally demanded sleep/wake schedule, despite adequate opportunity/ circumstances for sufficient daytime sleep. ${ }^{15}$ This condition may afflict nearly one third of shift workers, ${ }^{37}$ which has significant safety, health, and quality of life implications.

In simulation studies, shift work has been shown to result in impaired glucose tolerance, increased mean arterial blood pressure, and decreased levels of the satiety hormone, leptin. ${ }^{38}$ These changes occurred over a relatively short duration of 8 days. In a study involving nursing staff, those working the night shift were at increased risk of developing breast cancer. ${ }^{39}$ Nurses who worked the night shift for the longest duration were at greatest risk. In another study, shift work was associated with an increased risk of metabolic syndrome in both male and female nurses ${ }^{40}$ Clinical experience and surveys suggest increasing difficulty with sleep scheduling flexibility and the ability to work night shifts in association with advanced age (Table 2). ${ }^{41,42}$

\section{Assessment}

Various assessment tools can complement the clinical history in establishing a diagnosis of shift work sleep disorder.

Table 2 Factors related to development of shift work sleep disorder

\begin{tabular}{|c|c|}
\hline Factor & Impact \\
\hline Age & $\begin{array}{l}\text { Greater age tends to manifest less } \\
\text { adaptability to shift work, with greater } \\
\text { symptoms }\end{array}$ \\
\hline $\begin{array}{l}\text { Individual innate circadian } \\
\text { preference }\end{array}$ & $\begin{array}{l}\text { Morning preference has more difficult time } \\
\text { with night shift work; evening preference } \\
\text { adapt more easily to night shift work }\end{array}$ \\
\hline Endogenous molecular & Certain polymorphisms within CLOCK, \\
\hline clock mechanism & $\begin{array}{l}\text { NPAS2, PER2, and PER3 genes may be } \\
\text { associated with increased symptoms and } \\
\text { sleep inertia in shift workers }{ }^{163}\end{array}$ \\
\hline Sleep adaptation strategies & $\begin{array}{l}\text { Of several sleep strategies used in shift } \\
\text { workers, sleep deprivation to shift back } \\
\text { to nocturnal sleep on days off is associated } \\
\text { with more symptoms of shift work sleep } \\
\text { disorder }\end{array}$ \\
\hline Social support & $\begin{array}{l}\text { Home situations that allow for a protected } \\
\text { sleeping environment (quiet, dark, } \\
\text { comfortable, safe) may improve daytime } \\
\text { sleep and reduce symptoms }\end{array}$ \\
\hline
\end{tabular}

Either sleep logs or actigraphy are required to demonstrate stability of the complaint (and to rule out extraneous influences), but the latter typically generates more reliable data. ${ }^{43,44}$ Actigraphs are compact "motion detectors", used commonly in the clinical setting, the output of which allows longitudinal assessment of various sleep/wake parameters. ${ }^{45}$

\section{Treatment}

Treatment of shift work sleep disorder must rely on practical considerations. For example, if the shift work schedule is relatively stable it may be desirable to implement night-time light exposure and morning light shielding, in an effort to delay the circadian phase in a purposeful way. In contrast, this approach would not be logical in a worker who is assigned night shift for shorter periods, since this may represent a sort of "double jeopardy" wherein the patient is out of phase for both the short shift work period and the recovery period. In this latter case, strategies to minimize drowsiness at night and enhance sleep during the day during night shift periods may be more reasonable. A description of tools for treatment of shift work sleep disorder follows.

\section{Timed light exposure}

In an investigation by Boivin and James, ${ }^{46}$ nurses who received 6 hours of intermittent bright light (about 3000 lux) during night shifts and were shielded from morning outdoor light demonstrated significantly greater phase delays (desirable if complete reversal of days/nights is sought), as measured by core body temperature minimum. Work places could implement this strategy to reduce shift work sleep disorder among their workers. The lux is the unit of illuminance in the international system, whereby one lux is equal to the illumination of a single surface one meter away from a single candle. The illuminance of direct sunlight is 100,000 lux, but normal daylight, which is filtered through a cloudy sky, is between 5000 and 10,000 lux.

\section{Oral melatonin}

Data related to daytime (ie, night shift workers' sleep period) melatonin administration have produced mixed results in field settings, and study designs have typically not permitted differentiation with respect to hypnotic or phase-shifting effects, as reviewed by Sack et al. ${ }^{47}$ Favorable impacts on subjective sleep quality were described in two studies at doses ranging from $5 \mathrm{mg}$ to $6 \mathrm{mg} .{ }^{48,49}$ However, two other investigations demonstrated no such benefits at doses ranging from $6 \mathrm{mg}$ to $10 \mathrm{mg} .{ }^{50,51} \mathrm{In}$ a simulation study, melatonin 
provided no advantage over bright light and/or morning protective eyewear. ${ }^{52}$

\section{Hypnotics}

Both simulation and field studies have consistently described increased objective or subjective daytime sleep among those who received benzodiazepine receptor agonists. ${ }^{53-58}$ While one of the simulation protocols noted additional benefit in the ability to maintain alertness, ${ }^{55}$ two others noted no changes in sleepiness. ${ }^{53,54}$ No impairments in post sleep psychomotor performance were found subsequent to administration of $7.5 \mathrm{mg}$ zopiclone, a long-acting hypnotic. ${ }^{58}$

\section{Stimulants}

A large randomized placebo-controlled study of patients with shift work disorder conducted at multiple centers found that armodafinil at $150 \mathrm{mg}$, administered 30-60 minutes prior to a night shift, improved sleep latency on objective testing and improved subjective reports of wakefulness. This dosing schedule did not affect daytime sleep on polysomnography. ${ }^{59}$ Modafinil (200 mg), in a separate trial, demonstrated significant benefits over placebo with respect to objectively measured sleepiness, reaction time performance testing, and self-rated symptom improvement. ${ }^{60}$

A trial comparing the two medications in a sample of shift workers found comparable effects in terms of improvement in subjectively reported sleepiness at the end of shifts, as well as reported adverse effects. No objective measures of sleepiness were used. ${ }^{61}$ In another trial, caffeine at a dose of $4 \mathrm{mg} / \mathrm{kg}$ administered 30 minutes prior to a night shift, resulted in objective improvements in performance and alertness. ${ }^{62}$

\section{Other behavioral approaches}

Strategic napping, with naps of shorter duration (eg, 20 minutes or less) prior to the start of a shift, improved alertness during the shift and did not interfere with subsequent daytime sleep. ${ }^{63,64}$ Smith et al described a "compromise" phase position that strikes a balance between maintenance of a favorable circadian phase and continued participation in social and family activities. ${ }^{65}$ During their laboratory-based trial, participants were exposed to bright light for a short period immediately upon awakening to ensure their core body temperature minimum did not drift into the later part of the day and thus make it difficult for workers to stay up during these hours on their days off. On the day of their last shift, subjects slept for fewer hours to ensure a sufficient sleep drive that allowed for a sleep bout that is approximately 5.5 hours earlier. The above measures were complemented by exposure to bright light in the early part of the shift and protection from light exposure (with the use of dark glasses) while returning home from work. This schedule allowed for increased availability during conventional wake time hours, enhanced daytime sleep quality (by ensuring that it consistently encompassed core body temperature minimum), and improved performance during simulated work hours. Importantly, along with the aforementioned behavioral and pharmacological treatment, all shift workers should protect the daytime bedroom environment by ensuring that a quiet, dark, and undisturbed place is available for sleeping.

\section{Delayed sleep phase disorder Description and predisposing factors}

Delayed sleep phase disorder can be construed as a pronounced "night owl" circadian preference, such that those affected habitually retire and arise significantly later than conventional or desired clock times. Because the condition is felt to relate to an aberration in timing (but not quality) of sleep, the characterization of a disorder is invoked only if the schedule interferes significantly with social or occupational functioning. Primary considerations within the differential diagnosis include depression and anxiety, which often manifest with sleep complaints, ${ }^{66}$ as well as inadequate sleep hygiene, and numerous other conditions associated with sleep initiation complaints. There is recent evidence to suggest increased self-reported depressive symptoms in patients with delayed sleep phase syndrome. ${ }^{67}$ Primary insomnia can be differentiated from delayed sleep phase disorder with the patient's endorsement of readily initiating sleep when allowed to sleep on his/her desired sleep/wake schedule. The simultaneous presence of more than one condition seems to be the norm rather than the exception, and each need to be treated accordingly.

Delayed sleep phase disorder has been estimated to account for approximately $7 \%-16 \%$ of patients presenting with insomnia complaints in sleep medicine clinics. ${ }^{66,68}$ Results from these and other studies ${ }^{69-72}$ support the notion that the condition is much more common among younger cohorts, and the population prevalence among adolescents in particular has been reported at approximately $7 \%$ (Table 3$)^{73}$ The high frequency within this age group may be viewed as a pathological exaggeration of normal tendencies, because delays in the preferred timing of sleep and wakefulness in association with pubertal development have been described in the US and in numerous other industrial societies. ${ }^{74-78}$ Although this can in part be construed as consequent to 
Table 3 Factors related to the development delayed or advanced sleep phase disorder

\begin{tabular}{lll}
\hline $\begin{array}{l}\text { Advanced sleep } \\
\text { phase disorder }\end{array}$ & Factor & $\begin{array}{l}\text { Delayed sleep } \\
\text { phase disorder }\end{array}$ \\
\hline $\begin{array}{l}\text { Increased prevalence } \\
\text { in older age }\end{array}$ & Age & $\begin{array}{l}\text { Increased prevalence } \\
\text { in younger age, } \\
\text { especially adolescence } \\
\text { Possible increased }\end{array}$ \\
$\begin{array}{l}\text { Possible increased risk } \\
\text { in patients with morning } \\
\text { preference; certain }\end{array}$ & $\begin{array}{l}\text { Individual } \\
\text { innate circadian }\end{array}$ & $\begin{array}{l}\text { risk in patients with } \\
\text { polymorphisms in clock- } \\
\text { associated genes identified }\end{array}$ \\
\hline
\end{tabular}

changes in the psychosocial milieu, maturational changes in biological sleep processes also contribute. ${ }^{79-81} \mathrm{~A}$ unifying etiology has not yet been identified..$^{47,82-87}$

\section{Assessment}

The tools of assessment are identical to those described in association with shift work sleep disorder. Eveningness tendencies of presumptive delayed sleep phase disorder patients can be further verified with the Morningness-Eveningness Questionnaire (MEQ), the score of which corresponds to the endogenous circadian period or phase. ${ }^{88}$ Lower scores are associated with evening types, and can therefore be helpful in narrowing the differential diagnosis for sleep-initiation complaints (reviewed by Sack et $\mathrm{al}^{47}$ ).

\section{Treatment}

\section{Timed light exposure}

Research protocols involving patients with delayed sleep phase disorder have demonstrated that properly timed morning bright light therapy (ie, $\geq 2500$ lux) can result in physiologically measured phase advances, objective improvements in daytime alertness, and earlier reported bedtimes compared with controls. ${ }^{89}$ Although a minimum required duration of light therapy has not been established, most providers recommend at least 30 minutes daily, in accordance with protocols used for seasonal affective disorder. ${ }^{90}$ Daily postawakening treatment is met with dismal compliance among adolescents, ${ }^{91}$ because it requires yet an earlier wake time among youngsters presumably arising near the physiological nadir of sleepiness. ${ }^{92-94}$ This limits the clinical utility of this treatment modality.

\section{Oral melatonin}

There is abundant evidence to support the role of melatonin in achieving phase advances in those with delayed sleep phase disorder, and more recent evidence suggests an additional antidepressant effect. ${ }^{92,95-98}$ When used in combination with light therapy, a synergistic circadian effect can be achieved. The proper timing of melatonin to effect a maximal advance can be estimated based upon the individual's natural (ie, preferred) wake time, with dosing scheduled 8 hours thereafter. ${ }^{92}$ Doses of $0.5 \mathrm{mg}$ or less appear optimal with respect to achievement of maximal chronobiotic effect. ${ }^{99}$ Complicating matters, however, is the fact that pediatric patients and/or their caregivers are frequently reluctant recipients of this supplement because of concerns related to adverse effects on reproductive function and regulation of growth hormone. ${ }^{100-102}$ Reflective of the above, a long-term outcome study of adolescents with delayed sleep phase disorder demonstrated that the majority (66\%) pursued treatment for a median duration of only $2-5$ months, and only $17 \%$ of subjects were treated for 1 year or longer. ${ }^{91}$

\section{Chronotherapy}

Chronotherapy is a treatment whereby patients are prescribed a sleep schedule which is gradually delayed until the prescribed schedule is aligned to the desired sleep times. Once this objective is achieved, the individual is advised to maintain a regular sleep/wake schedule rigorously, repeating the process as necessary. Although there are positive case reports describing the use of chronotherapy for delayed sleep phase disorder, ${ }^{103}$ there have been no controlled trials of its efficacy or safety. One study assessing the long-term efficacy of this strategy reported that relapse was common. ${ }^{104}$ In addition, there is one report of a patient who developed free-running circadian rhythms after engaging in this treatment. ${ }^{105}$ Furthermore, clinical experience suggests that implementation is impractical for patients who require adherence to any semblance of a fixed schedule.

\section{Hypnotics}

There is limited evidence to support the use of hypnotics in delayed sleep phase disorder, ${ }^{104}$ and patients may exhibit resistance to their effects. ${ }^{106}$ Nevertheless, in individuals with a concomitant conditioned insomnia, they can serve in some instances to heighten confidence with respect to the ability to initiate sleep. No hypnotics are approved by the United States Food and Drug Administration for use within the pediatric population.

\section{Other behavioral approaches}

In the case of adolescents, a later school start time may be sought if practical and available within the school district. This intervention alone can often significantly increase 
total sleep time, and mitigate associated impairments. ${ }^{107,108}$ In all instances, external contributors to delayed sleep phase disorder complaints should be pursued and addressed, including poor sleep hygiene practices and/or substance misuse. Implementation of regular wake times should be emphasized, because later rise times on weekends can themselves cause phase delays. ${ }^{109}$ As can occur in anyone with chronic sleep initiation complaints, delayed sleep phase disorder patients may have a concomitant conditioned insomnia, which is often responsive to evidence-based behavioral treatments (reviewed by Morgenthaler et $\mathrm{al}^{110}$ ).

\section{Advanced sleep phase disorder Description and predisposing factors}

Advanced sleep phase disorder (the polar opposite of delayed sleep phase disorder) describes those who retire and arise earlier than desired/conventional clock times. ${ }^{15}$ Although not included among the actual criteria, sleep onset is described as "typically" occurring between 18:00 and 21:00 hours, with sleep offset between 02:00 and 05:00 hours.

Psychiatric, medical, or substance-induced conditions should not contribute to sleep problems primarily. Because the condition is classically related to an aberration in timing (but not quality) of sleep, the characterization of a disorder is invoked only if the schedule interferes significantly with social or occupational functioning. As with delayed sleep phase disorder, depression needs to be considered within the differential diagnosis. ${ }^{111}$ Poor sleep hygiene practices, particularly evening napping (reviewed further below) and irregularity of the sleep/wake schedule also need to be explored. Finally, as with any sleep disturbance that persists over time, a conditioned insomnia can develop secondarily. The presence of more than one contributing variable requires that each entity be treated accordingly.

In one large survey study that approximated stringent criteria (among a cohort aged 40-64 years), population prevalence was estimated at $1 \%$, although it is unclear what proportion of these subjects would deem their schedule to be significantly troublesome so as to warrant clinical attention, a requirement when invoking the disorder terminology. ${ }^{72}$ In contrast with delayed sleep phase disorder, elderly status appears to be a risk factor (Table 3). ${ }^{69,112}$

A pathophysiological correlate has been demonstrated among a cohort with familial advanced sleep phase disorder, in the form of a markedly shortened endogenous circadian period. ${ }^{113}$ Genetic analyses revealed a missense mutation in a casein kinase $(C K 1 \varepsilon)$ binding region of a Period gene (hPer2), culminating in hypophosphorylation by $C K 1 \varepsilon$ in vitro. ${ }^{114}$ While the importance of this finding cannot be overstated, genetic heterogeneity is apparent among these familial cases, as demonstrated by the fact that other cohorts from this ${ }^{114}$ and other studies ${ }^{115}$ did not reveal such a mutation. A separate report of a Japanese familial cohort described a missense mutation in a different casein kinase gene $(C K I \delta)$, which also resulted in decreased enzymatic activity in vitro. ${ }^{116}$

\section{Assessment}

As described for delayed sleep phase disorder, data obtained from sleep logs, actigraphy, and the MEQ can prove invaluable, in addition to a thorough clinical history. ${ }^{45,88,113,117}$ Higher scores on the MEQ are associated with morning types. ${ }^{47}$

\section{Treatment}

\section{Timed light exposure}

A variety of studies have employed evening light therapy for advanced sleep phase disorder (or for conditions approximating this complaint), according to underlying knowledge of the human light phase response curve (see Figure 2). In the two positive studies to date, compliance with treatment was systematically monitored, and physiological circadian markers were employed. ${ }^{118,119}$ In the first, bright light (4000 lux) was administered for two hours between 20:00 and 23:00 hours for 12 consecutive nights in subjects' homes. ${ }^{118}$ Significant phase delays were observed in the active treatment group (compared with the sham intervention group), on the order of 3 hours, in association with an average delay in bedtime of nearly 30 minutes, an approximately $13 \%$ increase in sleep efficiency (time asleep $\div$ time in bed), and a related decrease in wakefulness after sleep onset. In the more recent study, similar magnitudes of phase delays were achieved utilizing a lower intensity of light (2500 lux) and a shorter overall duration of treatment ( 2 nights), but with administration at a later clock time (20:00-01:00 hours) and with a greater length of exposure ( 2 hours). ${ }^{119}$

In an attempt to develop a protocol that was better tolerated and more practically implemented in the clinical setting, a separate group of investigators explored the efficacy of "enhanced evening light" (approximately 265 lux) administered by an apparatus resembling a floor lamp. ${ }^{117}$ The treatment was provided in subjects' homes for 2-3 hours at earlier clock times than described previously (19:00-22:00 hours) for a duration of 4 weeks. Although overall compliance was monitored during the protocol, the placement of the lighting device in relation to the participant was unsupervised, and no objective benefits were 
demonstrated compared with the placebo intervention. The importance of monitoring patient compliance and proper device utilization are further highlighted by two additional studies that more closely approximated the protocols of the aforementioned positive investigations, ${ }^{120,121}$ including one with an otherwise identical protocol to that described previously. ${ }^{119}$ Despite these and other limitations, subjective benefits of light therapy in the reviewed studies are uniformly observed, and there is little risk in implementing a trial of treatment.

The timing of sleep/darkness may also impact circadianbased sleep complaints. Evidence was recently provided for a darkness phase response curve such that exposure darkness (and/or sleep) during the hours of 19:00-01:00 resulted in phase advances. ${ }^{122}$ In a more naturalistic study of older subjects, those who took evening naps showed earlier sleep-offset times and a more advanced melatonin rhythm than subjects who refrained from napping. ${ }^{123}$ Because both behaviors (ie, evening naps and early awakenings) could theoretically result in phase advances (see Figure 2), both avoidance of evening naps and protection from morning light exposure are rational recommendations to provide to the patient. With respect to the latter intervention, the use of protective eyewear (approximately 15\% visual light transmission, $<3 \%$ blue light transmission) was shown to be effective in decreasing light exposure (and undesired phase advances) in studies involving subjects exposed to simulated shift work, ${ }^{52}$ and could logically be utilized among those with advanced sleep phase disorder.

\section{Oral melatonin}

There are no systematic reports of melatonin administration for those with advanced sleep phase disorder, ${ }^{124,125}$ but consideration of the melatonin phase response curve (nearly a mirror image of the light phase response curve, see Figure 3) provides a rationale for low-dose administration after early morning awakenings and/or upon final arising in the morning. ${ }^{126}$ Legitimate safety concerns arise when recommending a potentially sleep-promoting agent during morning hours, and appropriate precautions are required if this treatment is initiated. ${ }^{127}$

\section{Chronotherapy}

There is one case report of successful use of this modality in a patient with presumed advanced sleep phase disorder (an advance of 3 hours every 2 days for a 2 -week period), with successful maintenance of the desired phase at the 5-month follow-up assessment. ${ }^{128}$ As discussed for delayed sleep phase disorder, further research is required regarding the efficacy and practicality of this intervention in the clinical setting.

\section{Hypnotics}

Nightly administration of longer-acting agents (eg, eszopiclone) or intermittent dosing of shorter-acting agents in the early morning hours (eg, zaleplon) is occasionally helpful for patients with advanced sleep phase disorder. Taking into account the population typically affected by this complaint, eszopiclone (1-2 mg) has shown favorable safety and efficacy in a large randomized, controlled study of elderly medically stable individuals (mean age 72.3 years) with primary insomnia for a period of up to 2 weeks. ${ }^{129} \mathrm{~A}$ similar short-term study investigating the use of zaleplon $(5-10 \mathrm{mg}$ ) in elderly individuals (mean 72.5 years of age) was extended to a single-blinded, open-label phase, with favorable results up to 12 months. ${ }^{130}$

\section{Other behavioral approaches}

In all instances, external contributors to advance-related sleep complaints should be pursued and addressed, including avoidance of evening naps, ${ }^{123,131}$ as discussed above. As can occur in anyone with chronic sleep maintenance complaints, patients may develop a concomitant conditioned insomnia, which is often responsive to evidence-based behavioral treatments. ${ }^{110}$

\section{Irregular sleep-wake rhythm Description and predisposing factors}

Among those afflicted with an irregular sleep-wake rhythm, the timing of sleep and wakefulness is variable, and does not adhere to a particular pattern. ${ }^{15}$ This condition occurs most commonly in the demented population, and appears to be related to progressive neurodegeneration, as demonstrated by a study that showed a direct correlation between progressive sleep fragmentation and increased severity of Alzheimer's disease in community-dwelling patients. This study has been reviewed elsewhere by Vitiello et al. ${ }^{132}$

Potential pathophysiological correlates of sleep observations are numerous. A large study involving patients with a neuropathological diagnosis of Alzheimer's disease demonstrated significant postmortem differences in melatonin levels in cerebrospinal fluid, as compared with those in age-matched controls. ${ }^{133}$ When separating the patients with Alzheimer's disease by apolipoprotein E4 status, those who were homozygous demonstrated significantly lower levels of melatonin than those who were heterozygous. Given the known association between apolipoprotein $\mathrm{E} 4$ status and risk 
for development of Alzheimer's disease, the data suggest that decreased melatonin levels in the cerebrospinal fluid are inherent to the neurodegenerative process, although no relationship was demonstrated between melatonin levels and the onset, duration, or severity of dementia.

Circadian abnormalities may also occur at other points within the retinohypothalamic tract-suprachiasmatic nucleipineal axis. Although not a consistent finding, a series of case-control studies involving patients with a neuropathological diagnosis of Alzheimer's disease has demonstrated axonal degeneration in the optic nerve in $80 \%$ of patients and degeneration of retinal ganglion cells in 75\%, for an overall 36\% reduction in neuroretinal loss as compared with age-matched controls. ${ }^{134}$ A $60 \%$ reduction in the total suprachiasmatic nuclei numbers in patients with Alzheimer's disease as compared with age-matched controls has been demonstrated. Investigation of the specific nature of the pathological damage of the structure revealed neurofibrillary tangle formation, suggesting that damage to this region is an integral part of the neuropathological process of Alzheimer's disease, as discussed elsewhere. ${ }^{135}$ Finally, decreased exposure to environmental illumination has been demonstrated in both community-dwelling and institutionalized patients having varying severities of dementia ${ }^{136,137}$ with direct correlations to poor sleep in the more recent study. ${ }^{136}$

With respect to exogenous contributors, a study by Schnelle et $\mathrm{al}^{138}$ assessed a large number of residents in eight different nursing homes during daytime hours and observed that they were in bed during $36 \%$ of observations and asleep nearly $25 \%$ of the time. As opposed to nocturnal disturbances, such daytime behaviors may be unrecognized or of little concern to caregivers, but may precipitate sleep difficulties during night-time hours. Environmental noise related to activities in the workplace has also been shown to have deleterious effects on the sleep of institutionalized patients, as have nocturnal cares. ${ }^{138}$

\section{Assessment}

Evaluation for this circadian rhythm sleep disorder does not differ from that described for the other conditions, but cognitive status may require greater reliance on external informants/observers and objective measures (eg, actigraphy).

\section{Treatment}

\section{Timed light exposure}

The effects of bright light on sleep parameters in patients with irregular sleep-wake rhythm is equivocal. Confounding variables preclude direct comparison of these trials. In a large trial involving institutionalized patients with Alzheimer's disease, both evening and morning bright light (2500 lux, 2 hours' duration for each condition) administered for a period of 10 days was superior to sham treatment and resulted in improved sleep consolidation as measured by an actigraph. ${ }^{139}$ However, these results were not replicated in a more recent randomized controlled trial of institutionalized patients with Alzheimer's disease who received morning or afternoon bright light of similar intensity (2500 lux or greater, 1-hour duration for each condition), 5 days each week for a total of 10 weeks. ${ }^{140}$ Though these discrepant results are difficult to compare, on review of the cumulative data it appears that increased 24-hour light exposure, regardless of timing, may have beneficial effects on sleep and circadian rhythms.

\section{Oral melatonin}

A large, multicenter, placebo-controlled trial investigated the use of melatonin as a treatment for sleep disturbances in the population with Alzheimer's disease. ${ }^{141}$ While caregiverrated sleep quality improved modestly, there were no significant differences in actigraphy-derived sleep measures. Melatonin even at the highest dose administered (10 mg) was well tolerated.

\section{Hypnotics}

Sedative hypnotics are sometimes required in the elderly population, because of failure or impracticality of nonpharmacological treatments, as discussed previously by Bliwise. ${ }^{142}$ Unfortunately, few studies exist to guide the clinician in symptomatic treatment of insomnia in those with neurodegenerative diseases. A small pilot study of low-dose $(0.125 \mathrm{mg})$ triazolam in community-dwelling patients with Alzheimer's disease and sleep disturbances did not reveal any group effect on sleep parameters (as measured by actigraphy), although marked interindividual variability occurred. ${ }^{143}$ The drug was well tolerated and had no effect on a computerized assessment of short-term memory. In a study involving approximately 60 elderly patients with dementia (type unspecified), zolpidem (10-20 mg) significantly improved total sleep time compared with placebo over a 3-week period, as assessed by nurse responses to a questionnaire. ${ }^{144}$ The medication was well tolerated at lower doses, and rebound insomnia did not emerge after discontinuation in either active treatment group.

\section{Stimulants}

Curiously, one case report has described markedly improved sleep consolidation in a patient with Alzheimer's 
disease administered methylphenidate $20 \mathrm{mg}$ in divided doses during daytime hours. The mechanism underlying this observation is unclear.

\section{Other behavioral approaches}

Implementation of sleep hygiene principles is relatively simple and can likely result in significant benefits. One randomized trial involving incontinent nursing home patients compared a combination of daytime physical activity and night-time measures to mitigate sleep interruption with night-time measures alone. This study demonstrated improved sleep efficiency and reduced daytime observations in bed in patients who received both interventions. ${ }^{145}$ Another group, also utilizing a rigorous design, studied communitydwelling patients with Alzheimer's disease and examined the effects of caregiver-implemented sleep hygiene principles, increased physical activity, and daytime light exposure (administered via a light box). ${ }^{146}$ Patients participating in the active treatment group showed a significant reduction in night-time awakenings, as assessed by actigraphy, in addition to significantly decreased wake after sleep onset, and improved depression scores. Results were maintained at 6 months' follow-up with additional decreases in duration of night-time awakenings.

\section{Circadian rhythm sleep disorder: free-running type Description and predisposing factors}

This condition is characterized by a lack of synchronization between the internal circadian period and the 24-hour light/ dark cycle, such that the sleep-wake rhythm "free runs" which, in most instances, results in a gradual delay in sleepwake timing. ${ }^{15}$ The condition is quite common among the totally blind (without intact retinohypothalamic tracts), ${ }^{147}$ and is observed rarely among sighted individuals. ${ }^{47,105,147,148}$ A high proportion of the latter population has been observed to have comorbid psychiatric illness and/or delayed sleep phase disorder, which may confer risks for the free-running type by virtue of continuously low light levels and atypical schedules, thereby impeding entrainment. ${ }^{105,148,149}$

Table 4 Treatments for circadian rhythm sleep disorders

\begin{tabular}{|c|c|c|c|c|}
\hline $\begin{array}{l}\text { Circadian rhythm } \\
\text { disorder }\end{array}$ & Melatonin & Hypnotics & Stimulants & $\begin{array}{l}\text { Light therapy and other } \\
\text { behavioral treatments }\end{array}$ \\
\hline $\begin{array}{l}\text { Delayed sleep phase } \\
\text { disorder }\end{array}$ & $\begin{array}{l}0.5 \mathrm{mg} \text { given } 8 \text { hours } \\
\text { after preferred wake time }\end{array}$ & $\begin{array}{l}\text { Limited evidence } \\
\text { to support use }\end{array}$ & $\begin{array}{l}\text { Limited evidence } \\
\text { to support use }\end{array}$ & $\begin{array}{l}\text { Morning light exposure } \\
\text { ( } \geq 2500 \text { Lux) for } \geq 30 \text { minutes. } \\
\text { Prescribed sleep schedule that } \\
\text { is delayed progressively till desired } \\
\text { schedule is reached }\end{array}$ \\
\hline $\begin{array}{l}\text { Advanced sleep } \\
\text { phase disorder }\end{array}$ & $\begin{array}{l}\text { Limited evidence to } \\
\text { support use }\end{array}$ & $\begin{array}{l}\text { Limited evidence } \\
\text { to support use }\end{array}$ & $\begin{array}{l}\text { Limited evidence } \\
\text { to support use }\end{array}$ & $\begin{array}{l}\text { Bright light ( } \geq 2500 \text { Lux) } \\
\text { for } \geq 2-4 \text { hours in the evening. } \\
\text { Prescribed sleep schedule that } \\
\text { is advanced progressively till desired } \\
\text { schedule is reached }\end{array}$ \\
\hline $\begin{array}{l}\text { Irregular sleep-wake } \\
\text { rhythm }\end{array}$ & $\begin{array}{l}\text { Limited evidence to } \\
\text { support use }\end{array}$ & $\begin{array}{l}\text { Zolpidem } 10 \mathrm{mg} \text { at } \\
\text { nighttime in patients } \\
\text { with dementia }\end{array}$ & $\begin{array}{l}\text { A case report of } 20 \mathrm{mg} \\
\text { of methylphenidate } \\
\text { in divided doses during } \\
\text { the day }\end{array}$ & $\begin{array}{l}\text { Both evening and morning light } \\
\text { ( } 2500 \text { Lux) for } 2 \text { hours. } \\
\text { Daytime physical activity } \\
\text { and caregiver implemented sleep } \\
\text { hygiene may be helpful }\end{array}$ \\
\hline $\begin{array}{l}\text { Circadian rhythm } \\
\text { sleep disorder, } \\
\text { free-running type } \\
\text { Jet lag disorder }\end{array}$ & $\begin{array}{l}3 \mathrm{mg} \text { in sighted individuals } \\
\text { and } 0.5-10 \mathrm{mg} \text { in blind } \\
\text { subjects before bedtime. } \\
2-8 \mathrm{mg} \text {, prior to destination } \\
\text { sleep time, can be started } \\
\text { prior to travel versus on } \\
\text { arrival }\end{array}$ & $\begin{array}{l}\text { Limited evidence } \\
\text { to support use. } \\
\text { Zopiclone } 5 \mathrm{mg} / \\
\text { zolpidem } 10 \mathrm{mg} \text { prior } \\
\text { to sleep }\end{array}$ & $\begin{array}{l}\text { Limited evidence } \\
\text { to support use. } \\
\text { Modafinil at doses } \\
\text { of } 150 \mathrm{mg} \text {. } \\
\text { Caffeine } 300 \mathrm{mg}\end{array}$ & $\begin{array}{l}\text { Morning phototherapy in sighted } \\
\text { individuals. } \\
\text { Timed light exposure to prevent } \\
\text { antidromic effect }\end{array}$ \\
\hline Shift work disorder & $\begin{array}{l}\text { Evidence supporting use } \\
\text { is equivocal }\end{array}$ & $\begin{array}{l}\text { Zopiclone } 7.5 \mathrm{mg} \\
\text { prior to daytime } \\
\text { sleep bout. } \\
\text { Evidence also } \\
\text { for use of triazolam } \\
\text { and temazepam }\end{array}$ & $\begin{array}{l}\text { Aromdafinil } 150 / \text { modafinil } \\
200 \mathrm{mg} \text { prior to shift. } \\
\text { Caffeine } 4 \mathrm{mg} / \mathrm{kg} \text { prior } \\
\text { to shift }\end{array}$ & $\begin{array}{l}\text { Bright light ( } 3000 \text { lux) at the beginning } \\
\text { of shift. } \\
\text { Strategic short naps prior to shift } \\
\text { Protect sleep environment. } \\
\text { Be alert to opportunities to provide } \\
\text { recommendations for how to reduce } \\
\text { concomitant cardiovascular risks }\end{array}$ \\
\hline
\end{tabular}




\section{Assessment}

The tools of assessment are identical to those described in association with shift work sleep disorder. Actigraphy or sleep logs should demonstrate a stable pattern during successive observations. ${ }^{15}$ In instances where comorbid delayed sleep phase disorder is suspected, eveningness tendencies can be further verified with the MEQ,$^{88}$ as described above.

\section{Treatment}

\section{Timed light exposure}

Among sighted individuals with free-running type, morning light therapy has been described as a successful treatment within various case reports. ${ }^{149-152}$ Placebo-controlled trials have not been conducted.

\section{Oral melatonin}

Melatonin administered at the desired bedtime has demonstrated efficacy among both sighted and blind individuals with free-running type, as reviewed by Sack et al. ${ }^{124}$ Given the rarity of the condition within the former population, the associated data is less conclusive, but the most commonly utilized dosage was $3 \mathrm{mg}$, with the duration of treatment ranging from 1 month to 6 years. ${ }^{177,153-155}$ Within the blind population, two placebo-controlled trials have been published, utilizing doses ranging from $0.5-10 \mathrm{mg}$, for 3-9 weeks. ${ }^{156,157}$ Lower doses are equipotent to higher doses and, in some cases, may be more effective. ${ }^{158}$

\section{Other behavioral approaches}

There is one report of prescription of a sleep schedule for a free-running type patient, based upon physiological assessments of the underlying circadian period. ${ }^{159}$ Although sleep duration and quality significantly improved in this instance, it is not clear that a persistently free-running sleep-wake schedule would be accepted among the free-running type population at large, and physiological circadian markers are not routinely obtained clinically.

\section{Conclusion}

The successful management of circadian rhythm sleep disorders requires knowledge of underlying biological principles. Physiological phase assessments (such as those obtained by salivary melatonin immunoassays) appear to have potential utility, but are not yet routinely used clinically. ${ }^{47,124}$ Awareness of the pertinent phase response curves is therefore essential to the rational delivery of the mainstays of therapy, ie, oral melatonin and light therapy. Treatment strategies are summarized in Table 4. For those who elect to implement melatonin treatment, it should be noted that, apart from the concerns described above within the pediatric population, this substance is not regulated by the Food and Drug Administration, and is available overthe-counter as a nutritional supplement. Verification of purity of the product is therefore difficult. A comprehensive review of 48 studies by the National Academy of Sciences found that short-term use of melatonin in total daily doses $\leq 10 \mathrm{mg}$ in healthy adults, who are not on concurrent medication or dietary supplements, appears to be safe. Adverse effects have been reported at higher doses, and even at lower doses in those with pre-existing depression, chronic hepatic or renal failure, central nervous system, cardiovascular, gastrointestinal, or dermatological conditions. ${ }^{160}$ Among the studies reviewed herein that addressed potential side effects, none reported an incidence greater than that observed with placebo ${ }^{47}$ With respect to the provision of light therapy, there are no absolute contraindications, but caution should be taken in prescribing to those using photosensitizing drugs, history of mania triggered by light therapy, and/ or those with ocular or retinal pathology. ${ }^{47}$ Finally, while referral to a sleep specialist may be required to assist with care of these patients in most instances, it is our hope that the information provided assists with clinical assessment in primary care settings and stimulates heightened awareness of circadian abnormalities.

\section{Disclosure}

The authors report no conflicts of interest in this work.

\section{References}

1. Borbely AA, Achermann P. Concepts and models of sleep regulation: an overview. J Sleep Res. 1992;1(2):63-79.

2. Carskadon MA, Dement WC. Effects of total sleep loss on sleep tendency. Percept Mot Skills. 1979;48(2):495-506.

3. Moore RY, Eichler VB. Loss of a circadian adrenal corticosterone rhythm following suprachiasmatic lesions in the rat. Brain Res. 1972;42(1):201-206.

4. Welsh DK, Logothetis DE, Meister M, Reppert SM. Individual neurons dissociated from rat suprachiasmatic nucleus express independently phased circadian firing rhythms. Neuron. 1995;14(4): 697-706.

5. Ralph MR, Foster RG, Davis FC, Menaker M. Transplanted suprachiasmatic nucleus determines circadian period. Science. 1990;247(4945):975-978.

6. Czeisler CA, Duffy JF, Shanahan TL, et al. Stability, precision, and near-24-hour period of the human circadian pacemaker. Science. 1999;284(5423):2177-2181.

7. Waterhouse J, DeCoursey PJ. Chronobiology: Biological Timekeeping. Sunderland, MA: Sinauer Associates Inc Publishers; 2004.

8. Czeisler CA, Allan JS, Strogatz SH, et al. Bright light resets the human circadian pacemaker independent of the timing of the sleep-wake cycle. Science. 1986;233(4764):667-671

9. Mrosovsky N. Phase response curves for social entrainment. J Comp Physiol A. 1988;162(1):35-46. 
10. Hattar S, Liao HW, Takao M, Berson DM, Yau KW. Melanopsincontaining retinal ganglion cells: architecture, projections, and intrinsic photosensitivity. Science. 2002;295(5557):1065-1070.

11. Altimus CM, Guler AD, Alam NM, et al. Rod photoreceptors drive circadian photoentrainment across a wide range of light intensities. Nat Neurosci. 2010;13(9):1107-1112.

12. Waterhouse J, Drust B, Weinert D, et al. The circadian rhythm of core temperature: origin and some implications for exercise performance. Chronobiol Int. 2005;22(2):207-225.

13. Lewy AJ, Cutler NL, Sack RL. The endogenous melatonin profile as a marker for circadian phase position. J Biol Rhythms. 1999;14(3):227-236.

14. Borbely AA. A two process model of sleep regulation. Human Neurobiol. 1982;1(3):195-204.

15. American Academy of Sleep Medicine. International Classification of Sleep Disorders. Diagnostic and Coding Manual. 2nd ed. Westchester, IL: American Academy of Sleep Medicine; 2005.

16. Czeisler C, Duffy J, Shanahan T, et al. Stability, precision, and near-24-hour period of the human circadian pacemaker. Science. 1999;284(5423):2177-2181.

17. Eastman CI, Gazda CJ, Burgess HJ, Crowley SJ, Fogg LF. Advancing circadian rhythms before eastward flight: a strategy to prevent or reduce jet lag. Sleep. 2005;28(1):33-44.

18. Dawson D, Campbell SS. Timed exposure to bright light improves sleep and alertness during simulated night shifts. Sleep. 1991;14(6):511-516.

19. Moline ML, Pollak CP, Monk TH, et al. Age-related differences in recovery from simulated jet lag. Sleep. 1992;15(1):28-40.

20. Burgess HJ, Crowley SJ, Gazda CJ, Fogg LF, Eastman CI. Preflight adjustment to eastward travel: 3 days of advancing sleep with and without morning bright light. J Biol Rhythms. 2003;18(4): 318-328.

21. Muhm JM, Rock PB, McMullin DL, et al. Effect of aircraft-cabin altitude on passenger discomfort. N Engl J Med. 2007;357(1):18-27.

22. Lowden A, Akerstedt T. Retaining home-base sleep hours to prevent jet lag in connection with a westward flight across nine time zones. Chronobiol Int. 1998;15(4):365-376.

23. Eastman CI, Burgess HJ. How to travel the world without jet lag. Sleep Med Clin. 2009;4(2):241-255.

24. Edwards BJ, Atkinson G, Waterhouse J, Reilly T, Godfrey R, Budgett R. Use of melatonin in recovery from jet-lag following an eastward flight across 10 time-zones. Ergonomics. 2000;43(10): 1501-1513.

25. Petrie K, Dawson A, Thompson L, Brook R. A double-blind trial of melatonin as a treatment for jet lag in international cabin crews. Biol Psychiatry. 1993;33(7):526-530.

26. Suhner A, Schlagenhauf P, Johnson R, Tschopp A, Steffen R. Comparative study to determine the optimal melatonin dosage form for the alleviation of jet lag. Chronobiol Int. 1998;15(6):655-666

27. Paul MA, Gray G, Sardana TM, Pigeau RA. Melatonin and zopiclone as facilitators of early circadian sleep in operational air transport crews. Aviat Space Environ Med. 2004;75(5):439-443.

28. Arendt J, Aldhous M, Marks V. Alleviation of jet lag by melatonin: preliminary results of controlled double blind trial. Br Med J (Clin Res Ed). 1986;292(6529):1170.

29. Claustrat B, Brun J, David M, Sassolas G, Chazot G. Melatonin and jet lag: confirmatory result using a simplified protocol. Biol Psychiatry. 1992;32(8):705-711.

30. Petrie K, Conaglan J, Thompson L, Chamberlain K. Effect of melatonin on jet lag after long-haul flights. Br Med J. 1989;298(6675):705-707.

31. Jamieson AO, Zammit GK, Rosenberg RS, Davis JR, Walsh JK. Zolpidem reduces the sleep disturbance of jet lag. Sleep Med. 2001;2(5):423-430.

32. Hirschfeld U, Moreno-Reyes R, Akseki E, et al. Progressive elevation of plasma thyrotropin during adaptation to simulated jet lag: effects of treatment with bright light or zolpidem. J Clin Endocrinol Metab. 1996;81(9):3270-3277.
33. Daurat A, Benoit O, Buguet A. Effects of zopiclone on the rest/ activity rhythm after a westward flight across five time zones. Psychopharmacology (Berl). 2000;149(3):241-245.

34. Rosenberg RP, Bogan RK, Tiller JM, et al. A phase 3, double-blind, randomized, placebo-controlled study of armodafinil for excessive sleepiness associated with jet lag disorder. Mayo Clinic Proc. 2010;85(7): 630-638.

35. Pierard C, Beaumont M, Enslen M, et al. Resynchronization of hormonal rhythms after an eastbound flight in humans: effects of slow-release caffeine and melatonin. Eur J Appl Physiol. 2001;85(1-2):144-150.

36. Beaumont M, Batejat D, Pierard C, et al. Caffeine or melatonin effects on sleep and sleepiness after rapid eastward transmeridian travel. J Appl Physiol. 2004;96(1):50-58.

37. Drake CL, Roehrs T, Richardson G, Walsh JK, Roth T. Shift work sleep disorder: prevalence and consequences beyond that of symptomatic day workers. Sleep. 2004;27(8):1453-1462.

38. Scheer FA, Hilton MF, Mantzoros CS, Shea SA. Adverse metabolic and cardiovascular consequences of circadian misalignment. Proc Natl Acad Sci U S A. 2009;106(11):4453-4458.

39. Schernhammer ES, Laden F, Speizer FE, et al. Rotating night shifts and risk of breast cancer in women participating in the Nurses' Health Study. J Natl Cancer Inst. 2001;93(20):1563-1568.

40. Pietroiusti A, Neri A, Somma G, et al. Incidence of metabolic syndrome among night-shift healthcare workers. Occup Environ Med. 2010;67(1):54-57.

41. Harma MI, Hakola T, Akerstedt T, Laitinen JT. Age and adjustment to night work. Occup Environ Med. 1994;51(8):568-573.

42. Smith L, Mason C. Reducing night shift exposure: a pilot study of rota, night shift and age effects on sleepiness and fatigue. J Hum Ergol (Tokyo). 2001;30(1-2):83-87.

43. Bradshaw DA, Yanagi MA, Pak ES, Peery TS, Ruff GA. Nightly sleep duration in the 2-week period preceding multiple sleep latency testing. J Clin Sleep Med. 2007;3(6):613-619.

44. Varghese R, Slocumb NL, Silber MH, Auger RR. Comparative value of actigraphy versus sleep logs [Abstract]. Sleep. 2008; Suppl 31:A334-A335.

45. Morgenthaler TI, Alessi C, Friedman L, et al. Practice parameters for the use of actigraphy in the assessment of sleep and sleep disorders: an update for 2007. Sleep. 2007;30(4):519-529.

46. Boivin DB, James FO. Circadian adaptation to night-shift work by judicious light and darkness exposure. J Biol Rhythms. 2002;17(6): $556-567$.

47. Sack RL, Auckley D, Auger RR, et al. Circadian rhythm sleep disorders: part I, basic principles, shift work and jet lag disorders. An American Academy of Sleep Medicine review. Sleep. 2007;30(11): 1460-1483.

48. Folkard S, Arendt J, Clark M. Can melatonin improve shift workers' tolerance of the night shift? Some preliminary findings. Chronobiol Int. 1993;10(5):315-320.

49. Yoon IY, Song BG. Role of morning melatonin administration and attenuation of sunlight exposure in improving adaptation of night-shift workers. Chronobiol Int. 2002;19(5):903-913.

50. James M, Tremea MO, Jones JS, Krohmer JR. Can melatonin improve adaptation to night shift? Am J Emerg Med. 1998;16(4):367-370

51. Jorgensen KM, Witting MD. Does exogenous melatonin improve day sleep or night alertness in emergency physicians working night shifts? Ann Emerg Med. 1998;31(6):699-704.

52. Crowley SJ, Lee C, Tseng CY, Fogg LF, Eastman CI. Combinations of bright light, scheduled dark, sunglasses, and melatonin to facilitate circadian entrainment to night shift work. J Biol Rhythms. 2003;18(6):513-523.

53. Walsh JK, Sugerman JL, Muehlbach MJ, Schweitzer PK. Physiological sleep tendency on a simulated night shift: adaptation and effects of triazolam. Sleep. 1988;11(3):251-264.

54. Walsh JK, Schweitzer PK, Anch AM, Muehlbach MJ, Jenkins NA, Dickins QS. Sleepiness/alertness on a simulated night shift following sleep at home with triazolam. Sleep. 1991;14(2):140-146. 
55. Porcu S, Bellatreccia A, Ferrara M, Casagrande M. Performance, ability to stay awake, and tendency to fall asleep during the night after a diurnal sleep with temazepam or placebo. Sleep. 1997;20(7):535-541.

56. Puca FM, Perrucci S, Prudenzano MP, et al. Quality of life in shift work syndrome. Funct Neurol. 1996;11(5):261-268.

57. Monchesky TC, Billings BJ, Phillips R, Bourgouin J. Zopiclone in insomniac shiftworkers. Evaluation of its hypnotic properties and its effects on mood and work performance. Int Arch Occup Environ Health. 1989;61(4):255-259.

58. Moon CA, Hindmarch I, Holland RL. The effect of zopiclone $7.5 \mathrm{mg}$ on the sleep, mood and performance of shift workers. Int Clin Psychopharmacol. 1990;5 Suppl 2:79-83.

59. Czeisler CA, Walsh JK, Wesnes KA, Arora S, Roth T. Armodafinil for treatment of excessive sleepiness associated with shift work disorder: a randomized controlled study. Mayo Clinic Proc. 2009;84(11):958-972.

60. Czeisler CA, Walsh JK, Roth T, et al. Modafinil for excessive sleepiness associated with shift-work sleep disorder. $N$ Engl J Med. 2005;353(5):476-486.

61. Tembe DV, Dhavale A, Desai H, et al. Armodafinil versus modafinil in patients of excessive sleepiness associated with shift work sleep disorder: a randomized double blind multicentric clinical trial. Neurol Res Int. 2011;2011:514351.

62. Schweitzer PK, Randazzo AC, Stone K, Erman M, Walsh JK. Laboratory and field studies of naps and caffeine as practical countermeasures for sleep-wake problems associated with night work. Sleep. 2006;29(1):39-50.

63. Sallinen M, Harma M, Akerstedt T, Rosa R, Lillqvist O. Promoting alertness with a short nap during a night shift. J Sleep Res. 1998;7(4): 240-247.

64. Purnell MT, Feyer AM, Herbison GP. The impact of a nap opportunity during the night shift on the performance and alertness of 12-h shift workers. J Sleep Res. 2002;11(3):219-227.

65. Smith MR, Fogg LF, Eastman CI. A compromise circadian phase position for permanent night work improves mood, fatigue, and performance. Sleep. 2009;32(11):1481-1489.

66. Weitzman ED, Czeisler CA, Coleman RM, et al. Delayed sleep phase syndrome. A chronobiological disorder with sleep-onset insomnia. Arch Gen Psychiatry. 1981;38(7):737-746

67. Abe T, Inoue Y, Komada Y, et al. Relation between morningnesseveningness score and depressive symptoms among patients with delayed sleep phase syndrome. Sleep Med. 2011;12(7):680-684.

68. Regestein Q, Monk TH. Delayed sleep phase syndrome: a review of its clinical aspects. Am J Psychiatry. 1995;152(4):602-608.

69. Ando K, Kripke DF, Ancoli-Israel S. Delayed and advanced sleep phase symptoms. Isr J Psychiatry Relat Sci. 2002;39(1):11-18.

70. Schrader H, Bovim G, Sand T. The prevalence of delayed and advanced sleep phase syndromes. J Sleep Res. 1993;2(1):51-55.

71. Yazaki M, Shirakawa S, Okawa M, Takahashi K. Demography of sleep disturbances associated with circadian rhythm disorders in Japan. Psychiatry Clin Neurosci. 1999;53(2):267-268.

72. Ando K, Kripke DF, Ancoli-Israel S. Estimated prevalence of delayed and advanced sleep phase syndromes [Abstract]. Sleep Res. 1995;24:509.

73. Pelayo R, Thorpy M, Glvinsky P. Prevalence of delayed sleep phase disorder among adolescents. Sleep. 1988;17:392.

74. Wolfson A, Carskadon M. Sleep schedules and daytime functioning in adolescents. Child Dev. 1998;69(4):875-887.

75. Andrade MM, Benedito-Silva AA, Domenice S, Arnhold IJ, Menna-Barreto L. Sleep characteristics of adolescents: a longitudinal study. J Adolesc Health. 1993;14(5):401-406.

76. Laberge L, Petit D, Simard C, Vitaro F, Tremblay RE, Montplaisir J. Development of sleep patterns in early adolescence. J Sleep Res. 2001;10(1):59-67.

77. Giannotti F, Cortesi F, Sebastiani T, Ottaviano S. Circadian preference, sleep and daytime behaviour in adolescence. J Sleep Res. 2002;11(3):191-199.
78. Gau SF, Soong WT. The transition of sleep-wake patterns in early adolescence. Sleep. 2003;26(4):449-454.

79. Carskadon MA, Vieira C, Acebo C. Association between puberty and delayed phase preference. Sleep. 1993;16(3):258-262

80. Carskadon MA, Acebo C, Richardson GS, Tate BA, Seifer R. An approach to studying circadian rhythms of adolescent humans. J Biol Rhythms. 1997;12(3):278-289.

81. Jenni OG, Achermann P, Carskadon MA. Homeostatic sleep regulation in adolescents. Sleep. 2005;28(11):1446-1454.

82. Ancoli-Israel S, Schnierow B, Kelsoe J, Fink R. A pedigree of one family with delayed sleep phase syndrome. Chronobiol Int. 2001;18(5):831-840.

83. Campbell SS, Murphy PJ. Delayed sleep phase disorder in temporal isolation. Sleep. 2007;30(9):1225-1228.

84. Aoki H, Ozeki Y, Yamada N. Hypersensitivity of melatonin suppression in response to light in patients with delayed sleep phase syndrome. Chronobiol Int. 2001;18(2):263-271.

85. Uchiyama M, Okawa M, Shibui K, et al. Poor compensatory function for sleep loss as a pathogenic factor in patients with delayed sleep phase syndrome. Sleep. 2000;23(4):553-558.

86. Nagtegaal JE, Kerkhof GA, Smits MG, Swart AC, van der Meer YG. Traumatic brain injury-associated delayed sleep phase syndrome. Funct Neurol. 1997;12(6):345-348.

87. Patten SB, Lauderdale WM. Delayed sleep phase disorder after traumatic brain injury. J Am Acad Child Adolesc Psychiatry. 1992;31(1):100-102.

88. Horne JA, Ostberg O. A self-assessment questionnaire to determine morningness-eveningness in human circadian rhythms. Int $J$ Chronobiol. 1976;4(2):97-110.

89. Rosenthal NE, Joseph-Vanderpool JR, Levendosky AA, et al. Phase-shifting effects of bright morning light as treatment for delayed sleep phase syndrome. Sleep. 1990;13(4):354-361.

90. Wirz-Justice A, Benedetti F, Terman M. Chronotherapeutics for Affective Disorders: A Clinician's Manual for Light and Wake Therapy. Basel, Switzerland: S Karger AG; 2009.

91. Krahn LE, Kubas SM, Pankratz VS, Harris AM, Kotagal S. Long-term outcome of adolescents with delayed sleep phase disorder [Abstract]. Sleep. 2003;26:A115.

92. Mundey K, Benloucif S, Harsanyi K, Dubocovich ML, Zee PC. Phase-dependent treatment of delayed sleep phase syndrome with melatonin. Sleep. 2005;28(10):1271-1278.

93. Chang AM, Reid KJ, Gourineni R, Zee PC. Sleep timing and circadian phase in delayed sleep phase syndrome. J Biol Rhythms. 2009;24(4):313-321.

94. Cagnacci A, Elliott JA, Yen SS. Melatonin: a major regulator of the circadian rhythm of core temperature in humans. J Clin Endocrinol Metab. 1992;75(2):447-452.

95. Rahman SA, Kayumov L, Shapiro CM. Antidepressant action of melatonin in the treatment of delayed sleep phase syndrome. Sleep Med. 2010;11(2):131-136.

96. Dahlitz M, Alvarez B, Vignau J, English J, Arendt J, Parkes JD. Delayed sleep phase syndrome response to melatonin. Lancet. 1991;337(8750):1121-1124.

97. Dagan Y, Yovel I, Hallis D, Eisenstein M, Raichik I. Evaluating the role of melatonin in the long-term treatment of delayed sleep phase syndrome (DSPS). Chronobiol Int. 1998;15(2):181-190.

98. Kayumov L, Brown G, Jindal R, Buttoo K, Shapiro CM. A randomized, double-blind, placebo-controlled crossover study of the effect of exogenous melatonin on delayed sleep phase syndrome. Psychosom Med. 2001;63(1):40-48.

99. Lewy AJ, Emens JS, Lefler BJ, Yuhas K, Jackman AR. Melatonin entrains free-running blind people according to a physiological dose-response curve. Chronobiol Int. 2005;22(6): 1093-1106.

100. Luboshitzky R, Shen-Orr Z, Nave R, Lavi S, Lavie P. Melatonin administration alters semen quality in healthy men. J Androl. 2002;23(4):572-578. 
101. Szeinberg A, Borodkin K, Dagan Y. Melatonin treatment in adolescents with delayed sleep phase syndrome. Clin Pediatr (Phila). 2006;45(9):809-818.

102. Valcavi R, Zini M, Maestroni GJ, Conti A, Portioli I. Melatonin stimulates growth hormone secretion through pathways other than the growth hormone-releasing hormone. Clin Endocrinol (Oxf). 1993;39(2):193-199.

103. Czeisler CA, Richardson GS, Coleman RM, et al. Chronotherapy: resetting the circadian clocks of patients with delayed sleep phase insomnia. Sleep. 1981;4(1):1-21.

104. Ito A, Ando K, Hayakawa T, et al. Long-term course of adult patients with delayed sleep phase syndrome. Jpn J Psychiatry Neurol. 1993;47(3):563-567.

105. Oren DA, Wehr TA. Hypernyctohemeral syndrome after chronotherapy for delayed sleep phase syndrome. $N$ Engl J Med. 1992;327(24):1762.

106. Auger RR. Circadian Rhythm Sleep Disorder, Delayed Sleep Phase Type (Pediatric Case). Westchester, IL: American Academy of Sleep Medicine; 2008.

107. National Sleep Foundation. Adolescent Sleep Needs and Patterns: Research Report and Resource Guide. Washington, DC: National Sleep Foundation; 2000.

108. Wahlstrom K. Changing times: findings from the first longitudinal study of later high school start times. NASSP Bulletin. 2002;86(633):3-21.

109. Burgess HJ, Eastman CI. A late wake time phase delays the human dim light melatonin rhythm. Neurosci Lett. 2006;395(3): 191-195.

110. Morgenthaler T, Kramer M, Alessi C, et al. Practice parameters for the psychological and behavioral treatment of insomnia: an update. An American Academy of Sleep Medicine report. Sleep. 2006;29(11):1415-1419.

111. Ohayon M. Prevalence of DSM-IV diagnostic criteria of insomnia: distinguishing insomnia related to mental disorders from sleep disorders. J Psychiatr Res. 1997;31(3):333-346.

112. Carrier J, Monk TH, Buysse DJ, Kupfer DJ. Sleep and morningnesseveningness in the 'middle' years of life (20-59 y). J Sleep Res. 1997;6(4):230-237.

113. Jones C, Campbell S, Zone S, et al. Familial advanced sleep phase syndrome: A short-period circadian rhythm variant in humans. Nat Med. 1999;5(9):1062-1065.

114. Toh K, Jones C, He Y, et al. An hPer2 phosphorylation site mutation in familial advanced sleep phase syndrome. Science. 2001;291(5506):1040-1043.

115. Satoh K, Mishima K, Inoue Y, Ebisawa T, Shimizu T. Two pedigrees of familial advanced sleep phase syndrome in Japan. Sleep. 2003;26(4):416-417.

116. Xu Y, Padiath QS, Shapiro RE, et al. Functional consequences of a CKIdelta mutation causing familial advanced sleep phase syndrome. Nature. 2005;434(7033):640-644.

117. Palmer CR, Kripke DF, Savage HC Jr, Cindrich LA, Loving RT, Elliott JA. Efficacy of enhanced evening light for advanced sleep phase syndrome. Behav Sleep Med. 2003;1(4): 213-226.

118. Campbell SS, Dawson D, Anderson MW. Alleviation of sleep maintenance insomnia with timed exposure to bright light. J Am Geriatr Soc. 1993;41(8):829-836.

119. Lack L, Wright H, Kemp K, Gibbon S. The treatment of earlymorning awakening insomnia with 2 evenings of bright light. Sleep. 2005;28(5):616-623.

120. Suhner AG, Murphy PJ, Campbell SS. Failure of timed bright light exposure to alleviate age-related sleep maintenance insomnia. $J \mathrm{Am}$ Geriatr Soc. 2002;50(4):617-623.

121. Pallesen S, Nordhus IH, Skelton SH, Bjorvatn B, Skjerve A. Bright light treatment has limited effect in subjects over 55 years with mild early morning awakening. Percept Mot Skills. 2005;101(3): 759-770.
122. Buxton O, L'Hermite-Baleriaux M, Turek F, van Cauter E. Daytime naps in darkness phase shift the human circadian rhythms of melatonin and thyrotropin secretion. Am J Physiol Regul Integr Comp Physiol. 2000;278(2):R373-R382.

123. Yoon I, Kripke D, Elliott J, Youngstedt S, Rex K, Hauger R. Age-related changes of circadian rhythms and sleep-wake cycles. J Am Geriatr Soc. 2003;51(8):1085-1091.

124. Sack RL, Auckley D, Auger RR, et al. Circadian rhythm sleep disorders: part II, advanced sleep phase disorder, delayed sleep phase disorder, free-running disorder, and irregular sleep-wake rhythm. An American Academy of Sleep Medicine review. Sleep. 2007;30(11): 1484-1501.

125. Morgenthaler TI, Lee-Chiong T, Alessi C, et al. Melatonin for the treatment of advanced sleep phase disorder. Sleep. 2008;31(7):925.

126. Lewy AJ. Clinical applications of melatonin in circadian disorders. Dialogues Clin Neurosci. 2003;5(4):399-413.

127. Zee PC. Melatonin for the treatment of advanced sleep phase disorder [Letter to the Editor]. Sleep. 2008;31(7):923.

128. Moldofsky H, Musisi S, Phillipson EA. Treatment of a case of advanced sleep phase syndrome by phase advance chronotherapy. Sleep. 1986;9(1):61-65.

129. Scharf M, Erman M, Rosenberg R, et al. A 2-week efficacy and safety study of eszopiclone in elderly patients with primary insomnia. Sleep. 2005;28(6):720-727.

130. Ancoli-Israel S, Richardson G, Mangano R, Jenkins L, Hall P, Jones W. Long-term use of sedative hypnotics in older patients with insomnia. Sleep Med. 2005;6(2):107-113.

131. Buxton OM, L'Hermite-Baleriaux M, Turek FW, van Cauter E. Daytime naps in darkness phase shift the human circadian rhythms of melatonin and thyrotropin secretion. Am J Physiol Regul Integr Comp Physiol. 2000;278(2):R373-R382.

132. Vitiello M, Prinz P, Williams D, Frommlet M, Ries R. Sleep disturbances in patients with mild-stage Alzheimer's disease. J Gerontol. 1990;45(4):M131-M138.

133. Wu YH, Swaab DF. The human pineal gland and melatonin in aging and Alzheimer's disease. J Pineal Res. 2005;38(3):145-152.

134. Blanks J, Schmidt S, Torigoe Y, Porrello K, Hinton D, Blanks R. Retinal pathology in Alzheimer's disease. II. Regional neuron loss and glial changes in GCL. Neurobiol Aging. 1996;17(3): 385-395.

135. Hofman MA, Swaab DF. Living by the clock: the circadian pacemaker in older people. Ageing Res Rev. 2006;5(1):33-51.

136. Shochat T, Martin J, Marler M, Ancoli-Israel S. Illumination levels in nursing home patients: effects on sleep and activity rhythms. J Sleep Res. 2000;9(4):373-379.

137. Campbell S, Kripke D, Gillin J, Hrubovcak J. Exposure to light in healthy elderly subjects and Alzheimer's patients. Physiol Behav. 1988;42(2):141-144.

138. Schnelle J, Cruise P, Alessi C, Ludlow K, Al-Samarrai N, Ouslander J. Sleep hygiene in physically dependent nursing home residents: behavioral and environmental intervention implications. Sleep. 1998;21(5):515-523.

139. Ancoli-Israel S, Gehrman P, Martin J, et al. Increased light exposure consolidates sleep and strengthens circadian rhythms in severe Alzheimer's disease patients. Behav Sleep Med. 2003;1(1):22-36.

140. Dowling G, Hubbard E, Mastick J, Luxenberg J, Burr R, Van Someren E. Effect of morning bright light treatment for restactivity disruption in institutionalized patients with severe Alzheimer's disease. Int Psychogeriatr. 2005;17(2):221-236.

141. Singer C, Tractenberg R, Kaye J, et al. A multicenter, placebo-controlled trial of melatonin for sleep disturbance in Alzheimer's disease. Sleep. 2003;26(7):893-901.

142. Bliwise DL. Sleep disorders in Alzheimer's disease and other dementias. Clin Cornerstone. 2004;6 Suppl 1A:S16-S28.

143. McCarten J, Kovera C, Maddox M, Cleary J. Triazolam in Alzheimer's disease: pilot study on sleep and memory effects. Pharmacol Biochem Behav. 1995;52(2):447-452. 
144. Shaw S, Curson H, Coquelin J. A double-blind, comparative study of zolpidem and placebo in the treatment of insomnia in elderly psychiatric in-patients. J Int Med Res. 1992;20(2):150-161.

145. Alessi C, Yoon E, Schnelle J, Al-Samarrai N, Cruise P. A randomized trial of a combined physical activity and environmental intervention in nursing home residents: do sleep and agitation improve? J Am Geriatr Soc. 1999;47(7):784-791.

146. McCurry S, Gibbons L, Logsdon R, Vitiello M, Teri L. Nighttime insomnia treatment and education for Alzheimer's disease: a randomized, controlled trial. J Am Geriatr Soc. 2005;53(5):793-802.

147. McArthur AJ, Lewy AJ, Sack RL. Non-24-hour sleep-wake syndrome in a sighted man: circadian rhythm studies and efficacy of melatonin treatment. Sleep. 1996;19(7):544-553.

148. Boivin DB, Caliyurt O, James FO, Chalk C. Association between delayed sleep phase and hypernyctohemeral syndromes: a case study. Sleep. 2004;27(3):417-421.

149. Hayakawa T, Kamei Y, Urata J, et al. Trials of bright light exposure and melatonin administration in a patient with non-24 hour sleep-wake syndrome. Psychiatry Clin Neurosci. 1998;52(2):261-262.

150. Hoban TM, Sack RL, Lewy AJ, Miller LS, Singer CM. Entrainment of a free-running human with bright light? Chronobiol Int. 1989;6(4): 347-353.

151. Watanabe T, Kajimura N, Kato M, Sekimoto M, Hori T, Takahashi K. Case of a non-24 h sleep-wake syndrome patient improved by phototherapy. Psychiatry Clin Neurosci. 2000;54(3):369-370.

152. Oren DA, Giesen HA, Wehr TA. Restoration of detectable melatonin after entrainment to a 24-hour schedule in a 'free-running' man. Psychoneuroendocrinology. 1997;22(1):39-52.

153. Siebler M, Steinmetz H, Freund HJ. Therapeutic entrainment of circadian rhythm disorder by melatonin in a non-blind patient. J Neurol. 1998;245(6-7):327-328.
154. Kamei Y, Hayakawa T, Urata J, et al. Melatonin treatment for circadian rhythm sleep disorders. Psychiatry Clin Neurosci. 2000;54(3):381-382.

155. Okawa M, Uchiyama M, Ozaki S, et al. Melatonin treatment for circadian rhythm sleep disorders. Psychiatry Clin Neurosci. 1998;52(2):259-260.

156. Sack RL, Brandes RW, Kendall AR, Lewy AJ. Entrainment of freerunning circadian rhythms by melatonin in blind people. $N$ Engl $J$ Med. 2000;343(15):1070-1077.

157. Lockley SW, Skene DJ, James K, Thapan K, Wright J, Arendt J. Melatonin administration can entrain the free-running circadian system of blind subjects. J Endocrinol. 2000;164(1):R1-R6.

158. Lewy AJ, Emens JS, Sack RL, Hasler BP, Bernert RA. Low, but not high, doses of melatonin entrained a free-running blind person with a long circadian period. Chronobiol Int. 2002;19(3):649-658.

159. Sack RL, Lewy AJ, Blood ML, Keith LD, Nakagawa H. Circadian rhythm abnormalities in totally blind people: incidence and clinical significance. J Clin Endocrinol Metab. 1992;75(1):127-134.

160. Committee on the Framework for Evaluating the Safety of Dietary Supplements FaNB, Board on Life Sciences, Institute of Medicine and National Research Council of the National Academies. Dietary Supplements: A Framework for Evaluating Safety. Washington, DC: The National Academies Press; 2005.

161. Beersma DG, Gordijn MC. Circadian control of the sleep-wake cycle. Physiol Behav. 2007;90(2-3):190-195.

162. Burgess HJ, Eastman CT. Prevention of Jet Lag. 2010. Available from http://pier.acponline.org/physicians/screening/prev1015/prev1015. html. Accessed January 12, 2012.
ChronoPhysiology and Therapy

\section{Publish your work in this journal}

ChronoPhysiology and Therapy is an international, peer-reviewed, open access journal focusing on research into the cyclic variations and rhythmicity in physiological processes in the body and the research and development and optimal timing of administration of therapeutic targets to achieve improved outcomes and quality of life for the patient. The

\section{Dovepress}

manuscript management system is completely online and includes a very quick and fair peer-review system. Visit http://www.dovepress.com/ testimonials.php to read real quotes from published authors. 